\title{
A comparative finite analysis of the mechanical behavior of ProTaper NEXT and WaveOne rotary files
}

\author{
Nada Omar ${ }^{1}$, Amira Galal Ismail ${ }^{1}$, Manar Galal ${ }^{1}$, Mohamed H. Zaazou ${ }^{2 *}$ and Mohamed Abdullah Mohamed ${ }^{1}$
}

\begin{abstract}
Finite element analysis was used to evaluate the stress distribution, estimate the residual stresses, bending, and amount of displacement of two nickel-titanium instruments manufactured by the same M-wire technology but with different cross-section.

Materials and methods: Two brands of Ni-Ti instruments ProTaper NEXT (Dentsply Maillefer), and WaveOne (Dentsply Maillefer, Ballaigues, Switzerland) were scanned with stereomicroscope to produce a two-dimensional model for each file using computer-aided design programs (CAD) (SolidWorks software package), which then was converted into stereolithographic extension to be readable by programming software (MATLAB software) to produce three-dimensional models. The mathematical analysis of files was performed on SolidWorks software package. The mechanical behavior of the two files was analyzed numerically in a SolidWorks package to simulate and measure torsion, bending, and file displacement. Application of a shear moment (torsion) $2.5 \mathrm{~N} / \mathrm{mm}$ moment of force was applied to the shaft in a clockwise direction, while the last $4 \mathrm{~mm}$ of the tip was rigidly constrained to evaluate the stress distribution on each file. As for Cantilever bending, a concentrated load of $1 \mathrm{~N}$ at the tip of the file with its shaft rigidly held in place was applied for the finite element models. The vertical displacement was measured and the von Mises stress distribution was evaluated.
\end{abstract}

Results: The WaveOne file showed higher torsional stresses accumulation than those accumulated in the ProTaper NEXT. While the ProTaper NEXT showed more bending and file displacement than those showed by WaveOne file.

Conclusions: The two files rotary models highlighted the different mechanical properties of the files although they share the same manufactured technology M-wire. The ProTaper NEXT showed less torsional stress accumulation and more bending properties.

Keywords: Finite element analysis, NiTi rotary files, ProTaper NEXT, WaveOne, Torsion stresses, Bending, File displacement

\section{Introduction}

Nickel-titanium (NiTi) rotary instruments are preferred than other endodontic instruments during the mechanical preparation of the root canal system due to their high flexibility (Walia et al., 1988), their tendency of being able to stay more centered in the canal (Esposito \& Cunningham, 1995), and preparing the canal within its original axis, causing less canal transportation (Glossen et al., 1995). In spite of these advantages, rotary $\mathrm{NiTi}$ files have major complications, concerning their fracture or separation within the canal during root canal shaping. The exact reason for $\mathrm{NiTi}$ instrument fracture can be

\footnotetext{
* Correspondence: mohamedzaazou@yahoo.com

${ }^{2}$ Restorative Dentistry, National Research Centre, Dokki, Egypt

Full list of author information is available at the end of the article
}

explained by various factors, the most critical factors are root canal morphology, instrument geometry, and operator experience (Haapasalo \& Shen, 2013). NiTi instruments may separate during root canal preparation due to one or maybe a combination of two ways: either by flexural fatigue and/or torsional stresses fatigue. When part of the instrument becomes locked in the canal while the shank of the instrument continues to rotate, torsional fracture occurs. If the elastic limit of the NiTi instrument increased while the instrument was locked in the canal then the instrument will definitely fracture (Sattapan et al., 2000).

The NiTi instrument designs, cross-sections, tapering, and metallurgical processing became different through several generations, in trials of finding an 


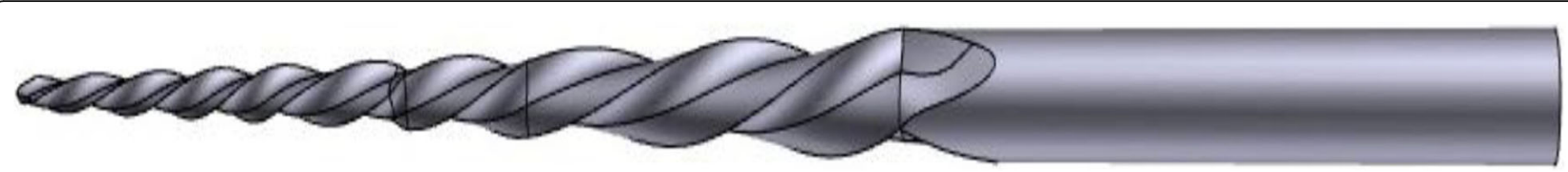

Fig. 1 WaveOne 3D model diagram

efficient, and safe instrument for preparing the root canal space (Haapasalo \& Shen, 2013).

Heat treatments or thermal processing of NiTi results in instruments with higher resistance to stress and fatigue (Haapasalo \& Shen, 2013). In 2007, Dentsply Tulsa first introduced to the market the M-wire technology. $\mathrm{M}$-wire is produced by undergoing a series of heat treatments to the NiTi file blanks before the file is machined into its final geometry (Haapasalo \& Shen, 2013).

NiTi instruments with increased flexibility will diminish procedural errors during canal preparation as canal transportation, improving the efficiency and safety of root canal preparation (Gambarini, 2001). Some factors influence the flexibility of NiTi rotary instruments are instrument cross-section, geometry, the composition, and technology of thermomechanical treatment of the metallic alloy (Al-Hadlaq et al., 2010; Gao et al., 2012; Lopes et al., 2013). Many studies have reported that more centered preparations within the root canal long axis were produced when highly flexible fileswere used in their preparation (Gergi et al., 2010; Short et al., 1997). Many manufacturing strategies and methodologies have been developed for NiTi rotary instruments to improve their flexibility and resistance to fracture. (Elnaghy, 2014; Lopes et al., 2013; Park et al., 2010)

The WaveOne (Dentsply Maillefer, Ballaigues, Switzerland) is a single file system where the tip of the file has a modified convex triangular cross-section, while the coronal end has a convex triangular cross-section. It was manufactured with $\mathrm{M}$-wire technology which involves special thermal processing of the metal improving its flexibility and resistance to cyclic fatigue (Al-Hadlaq et al.,

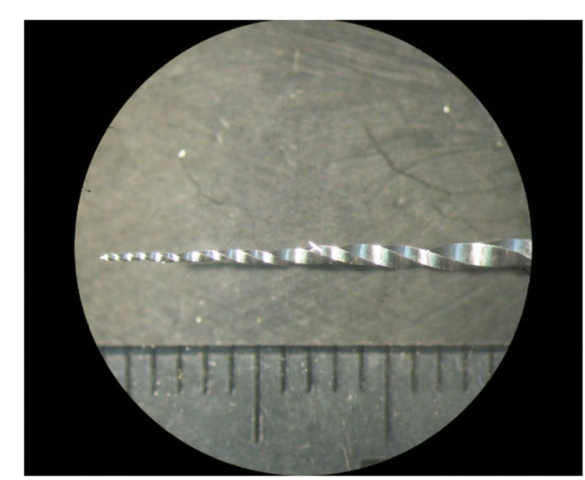

Fig. 2 Stereomicroscope imaging for protaper next
2010). Other development in file system with the same Mwire technology was the ProTaper NEXT (Dentsply Maillefer, Ballaigues, Switzerland) with rectangular crosssection design for greater strength, progressive tapering along the length of the file, M-wire technology that increased flexibility, and offset design which is used in continuous motion, rendering the file moves in swaggering motion. That reduces engagement of the file in the canal, which limits undesirable taper lock (Ruddle et al., 2013).

\section{Aim of the study}

The present study was conducted to evaluate and compare the mechanical properties of ProTaper NEXT (PTN) and WaveOne (WO) Ni-Ti rotary systems regarding bending, displacement during bending and torsion forces accumulated in the files using finite element analysis.

\section{Materials and methods Image analysis}

Image analysis was done using stereomicroscope to obtain a 3D image using Stereomicroscope scanning, PTN $\times 2$ size 25.06 and WaveOne primary file (25.08 taper). Each file was imaged at $\times 5, \times 10$, and $\times 16$ magnifications to obtain a detailed shape and accurate measurement of the files (Galal et al., 2015). The following data was collected and tabulated for each file: cross-section, working length, taper, number of flutes, and tip's diameter (Galal et al., 2015).

\section{Geometric analysis of the files}

Using the digital images obtained via stereomicroscope, the following data was collected and tabulated for each file: cross-section, working length, taper, number of flutes, and tip's diameter (Galal et al., 2015).

\section{Construction of 3D model Classic modeling using CAD programs}

To build the file's model, the file cross-section was drawn in 2D using computer-aided design programs (CAD) (SolidWorks software package). The 2D file with (.prt) extension was converted into Stereolithographic (.stl) extension to be readable by programming software (MATLAB software) (Galal et al., 2015).

\section{$3 D$ modeling using MATLAB software (Fig. 1)}

The building of the $3 \mathrm{D}$ model in form of sections was performed by MATLAB software using the following 


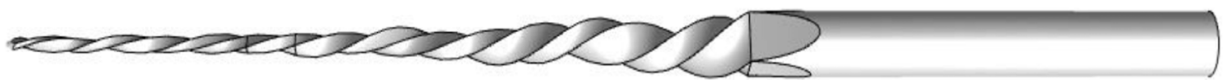

Fig. 3 ProTaper NEXT 3D model

data: taper of the file, change in pitch length, crosssection changes (Galal et al., 2015).

\section{4- Finite element models}

Using computer-aided design programs (CAD) (SolidWorks software package), finite element (FE) models for each file was created (Figs. 2 and 3). The meshing of the models (Fig. 4) was done by (SolidWorks software package) (Galal et al., 2015).

\section{Mathematical analysis of FE models}

The mathematical analysis of files was performed on SolidWorks software package. The mechanical behavior of the NiTi files was analyzed numerically in a SolidWorks package to simulate and measure Bending and Torsion (Galal et al., 2015).

\section{Bending}

Cantilever bending was simulated for the FE models by applying a concentrated load of $1 \mathrm{~N}$ at the tip of the file with its shaft rigidly held in place. The vertical displacement was measured and the von Mises stress distribution was evaluated (Kim et al., 2009a).

\section{Torsion}

Application of a shear moment (torsion) $2.5 \mathrm{~N} / \mathrm{mm} \mathrm{mo-}$ ment of force was applied to the shaft in a clockwise direction, while the last $4 \mathrm{~mm}$ of the tip was rigidly constrained. The stress distribution was evaluated (Kim et al., 2009a).

\section{Results}

Finite element analysis

Bending test

During bending test the von Mises stress on ProTaper NEXT FE model recorded $923 \mathrm{MPa}$ bending stresses, which was higher than that recorded in WaveOne FE model that recorded $583.1 \mathrm{MPa}$ as shown in Table 1, and the distributions of Von Mises bending stresses were illustrated in Figs. 5 and 6.

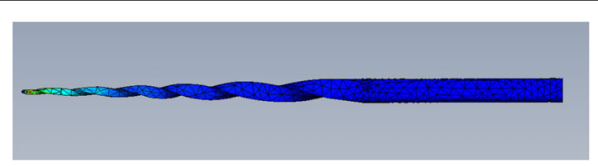

Fig. 4 Finite element model of the file

\section{Displacement during bending}

ProTaper NEXT FE model was displaced more than the WaveOne FE mode recording $11 \mathrm{~mm}$ and $4.5 \mathrm{~mm}$ respectively as shown in Table 2 .

\section{Torsion test}

During torsion test WaveOne FE model recorded 753.7 MPa Von Mises stresses, which was more than that in ProTaper NEXT FE model $608 \mathrm{MPa}$ as shown in Table 3 , and the distributions of von Mises torsion stresses was illustrated in Figs. 7 and 8.

\section{Discussion}

Finite element analysis or any other mathematical simulation analysis may show a difference from the clinical situation. Some conditions were not taken into consideration, such as eventually gradients of temperature, dentine walls friction with the instrument used, and complicated root canal anatomy. On the other hand, the applied loads and boundary conditions for both tested file models might give reliable indication about their expected clinical performance (Varghese et al., 2016).

This study compared the mechanical properties of PTN and WO NiTi instruments that share the same manufacturing technique by using $\mathrm{M}$-Wire technology with a rectangular cross-section design and asymmetric rotary motion for the PTN, and the modified convex triangular cross-section at the tip end and a convex triangular cross-section at the coronal end for the WO file.

The amount of torsional stresses accumulated in the tested NiTi files depends on their cross-sectional design, chemical composition of alloy, and thermo-mechanical technology applied during manufacturing (Kim et al., 2009b; Kim et al., 2009a; Turpin et al., 2000). The size of the instrument in the canal also has a significant influence on the amount of torsional load on the file (Peters et al., 2003).

In this study to simulate the repetitive locking of NiTi files during canal preparation, a shear moment (torsion) $2.5 \mathrm{~N} / \mathrm{mm}$ moment of force was applied to the shaft of the

Table 1 The maximum von Mises stress during bending of different files

ProTaper NEXT $923 \mathrm{MPa}$

WaveOne $583.1 \mathrm{MPa}$ 


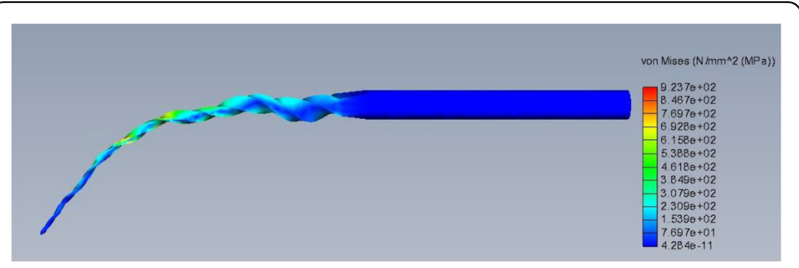

Fig. 5 Stress distribution during bending of ProTaper NEXT

tested files in a clockwise direction, while the last $4 \mathrm{~mm}$ of the tip was rigidly constrained using the $\mathrm{FE}$ analysis.

As mentioned before, the file cross-section is a major parameter that affects the instrument lifespan, as the shape of the cross-section and the angles that contact dentinal walls while cutting, directly affect the cutting efficiency of instrument (Peters et al., 2003).

This supports the hypothesis and findings in the current study. Where the WO and PTN share the same M-wire manufacture technology, but with different cross-sections, as mentioned before.

Therefore, by mathematical and mechanical principles, the PTN has a larger cross-section area that resists failures better than the smaller one that goes for the WaveOne model.

The WO cross-sectional design allows more stress accumulation in the file model of maximum von Mises stress during torsion testing of value $753.7 \mathrm{MPa}$, while the larger rectangular cross-section of PTN showed 608 $\mathrm{MPa}$ von Mises stress during torsion testing.

This supports the less torsion stress values so obtained for PTN as compared to WaveOne model. Kim et al. reported that under torsional stresses, the NiTi files were affected by many factors, such as the shape and geometry of the cross-section, radial land, and area of the continuous inner core (Kim et al., 2009b). The combination of these factors on the distribution of stresses along the length of the endodontic files under torsion remains undetermined. The present study showed that the effect of the alloy is less important than the crosssection geometry. There are numerous studies relating cross-section diameter to the torsional resistance (Ninan E, Berzins D W (Ninan \& Berzins, 2013) Wycoff R C

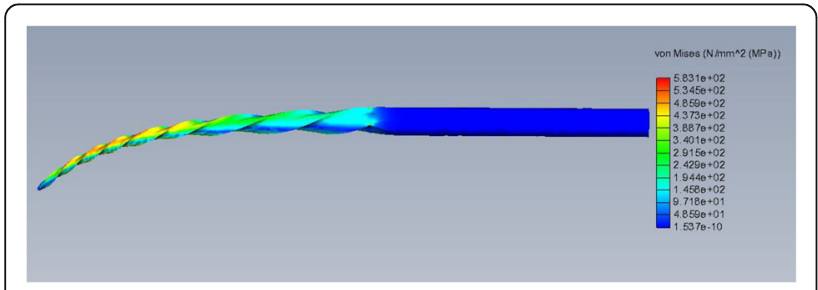

Fig. 6 Stress distribution during bending of WaveOne
Table 2 showing the displacement during bending of both files

\begin{tabular}{ll}
\hline ProTaper NEXT & $11 \mathrm{~mm}$ \\
WaveOne & $4.5 \mathrm{~mm}$ \\
\hline
\end{tabular}

and Berzins D.W (Wycoff \& Berzins, 2012), Camara AS et al. (Camara et al., 2009), and M. Prados-Privado et al. (Prados- Privado et al., 2019)).

These previous studies concluded that the bigger the cross-sectional diameter of the rotary instruments, the higher the torsional resistance. In other words, less torsion stresses accumulated within the files during cutting (Aggarwal et al., 2017). This also was found the same correlation in the present study.

The degree of flexibility of NiTi rotary instruments is a crucial property in predicting the mechanical behavior and performance of endodontic instruments during the preparation of curved canals (Lopes et al., 2013).

In 1981, the American Dental Association (ADA) stated that the taper of endodontic files as 0.02 taper, and allowed the variation within $0.05 \mathrm{~mm}$ in 2001 (Chesler et al., 2013). So there are three types of tapers: constant taper, decreasing taper, and progressive taper (from apical to coronal) (Gergi et al., 2012; Schafer \& Vlassis, 2004). It is declared that the files with progressive taper increase their flexibility, while decreasing taper turns the files much stiffer (Bergmans et al., 2003).

In the current study, the two instrument models were fixed $4 \mathrm{~mm}$ away from the tip because this represents the maximum tension for instruments yielding to bending, as the maximum curvature is found in the majority of root canals corresponding to that point. The PTN showed higher bending $923 \mathrm{MPa}$, and displacement of the file model with $11 \mathrm{~mm}$ in comparison to the WaveOne $583.1 \mathrm{MPa}$ and $4.5 \mathrm{~mm}$, respectively.

The WO file has a decreasing taper while the PTN has a progressive taper at the apical section while a decreasing taper at the coronal section (Capar et al., 2014), which makes the PTN model more flexible than WO model at the apical part as shown in Figs. 7 and 8. This supports our results despite both tested files are constructed by the same M-wire technology with microstructure is mainly consisted of martensite displays flexible and ductile properties (Shen et al., 2013).

Table 3 The maximum von Mises stress during torsion testing of both files

\begin{tabular}{ll}
\hline ProTaper NEXT & $608 \mathrm{MPa}$
\end{tabular}

WaveOne $753.7 \mathrm{MPa}$ 


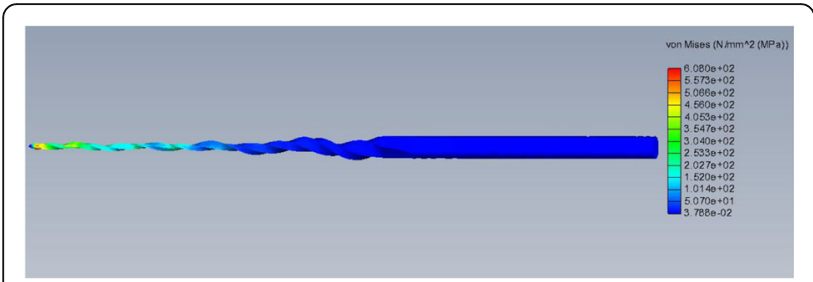

Fig. 7 Stress distribution during torsion test of ProTaper NEXT

The higher taper of WO with $8 \%$ taper at the tip making it more rigid with less bending and subsequently less file displacement. While the PTN file has 6\% taper with asymmetric rotary motion, which renders the file more flexible for bending and thus results in more displacement (Elnaghy, 2014; Schafer \& Vlassis, 2004). This supports the results conducted from the present study. This comes in agreement with Wu et al. (Wu et al., 2015).

\section{Conclusions}

Within the limitations of this study, numerical comparison by 3-dimensional finite element models had evaluated the effect of the torsion stresses, bending and displacement of the two studied endodontic file models, sharing equivalent size, and same technology of manufacturing (M-wire) but different cross-section diameter and taper.

The two studied endodontic files showed different mechanical behavior during simulated bending and torsion loadings. There is a difference in the areas for the maximum stress concentration within the file models, and in the value and distribution of the residual stresses for various instrument designs due to different crosssection and taper for each tested file.

It is significant for clinicians to know the features and characteristics of different NiTi rotary systems and their proper implications for use according to the different clinical conditions of root canal systems and to the manufacturers' directions of use.

Further numerical, experimental, and clinical investigations will be helpful in the evaluation of the mechanical behavior of different endodontic NiTi instruments and their clinical benefits and eventual negative consequences in root canal preparation.

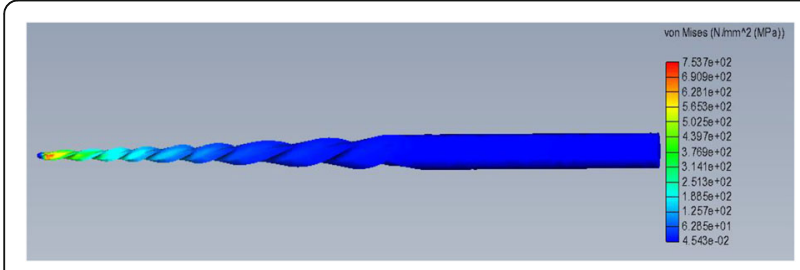

Fig. 8 Stress distribution during torsion test of WaveOne

\section{Abbreviations}

ADA: American Dental Association; CAD: Computer-aided design programs; FE: Finite element; MPa: Mega Pascale; NiTi: Nickel-titanium; PTN: ProTaper NEXT; stl: Stereolithographic; WO: WaveOne

\section{Acknowledgements}

Not applicable

Authors' contributions

All authors read and approved the final manuscript.

Funding

Not applicable

\section{Availability of data and materials}

Files are available at Dentsply, Cairo, Egypt. Computer-aided design programs (SolidWorks software package.

Ethics approval and consent to participate

Not applicable

\section{Consent for publication}

Not applicable

\section{Competing interests}

The authors declare that they have no competing interests.

\section{Author details}

${ }^{1}$ Researcher of Endodontics, Restorative and Dental Materials Department, National Research Centre, Dokki, Egypt. ${ }^{2}$ Restorative Dentistry, National Research Centre, Dokki, Egypt.

Received: 1 June 2019 Accepted: 20 August 2019

Published online: 10 October 2019

\section{References}

Aggarwal V, Arora V, Gupta S (2017) Comparative evaluation of dynamic torsional resistance of the nickel titanium instruments manufactured with different technologies. Int J applied dental sciences 3:202-205

Al-Hadlaq SM, Aljarbou FA, AlThumairy RI (2010) Evaluation of cyclic flexural fatigue of M-wire nickel-titanium rotary instruments. J Endod 36:305-307

Bergmans L, Van Cleynenbreugel J, Beullens M, Wevers M, Van Meerbeek B, Lambrechts P (2003) Progressive versus constant tapered shaft design using NiTi rotary instruments. Int Endod J. 36:288-295

Camara AS, Martins RC, Viana AC, Toledo Leonardo RD, Buono VTP, Azevedo Bahia MG (2009) Flexibility and torsional strength of protaper and protape universal rotary instruments assessed by mechanical tests. J Endod 35:113-116

Capar ID, Ertas H, Ok E, Arslan H (2014) Comparison of single cone obturation performance of different novel nickel-titanium rotary systems. Acta Odontol Scand. 72:537-542

Chesler MB, Tordik PA, Imamura GM, Goodell GG (2013) Intramanufacturer diameter and taper variability of rotary instruments and their corresponding Gutta-percha cones. J Endod. 39:538-541

Elnaghy AM (2014) Cyclic fatigue resistance of ProTaper Next nickel-titanium rotary files. Int Endod J 47:1034-1039

Esposito PT, Cunningham CJ (1995) A comparison of canal preparation with nickel-titanium and stainless steel instruments. J Endod. 21:173-176

Galal M, Nassef T, Saber S, Zaazou M, El-Ashry S (2015) Stress distribution of three NiTi rotary files under bending and torsional conditions using a Finite Element Analysis. Ain Shams medical journal

Gambarini G (2001) Cyclic fatigue of ProFile rotary instruments after prolonged clinical use. Int Endod J 34:386-389

Gao Y, Gutmann JL, Wilkinson K et al (2012) Evaluation of the impact of raw materials on the fatigue and mechanical properties of ProFile Vortex rotary instruments. J Endod 38:398-401

Gergi R, Abou RJ, Osta N, Sader J, Naaman A (2012) Taper preparation variability compared to current taper standards using computed tomography. Int J Dent. 2012:265-695

Gergi R, Rjeily JA, Sader J, Naaman A (2010) Comparison of canal transportation and centering ability of twisted files, Pathfile-ProTaper system, and stainless steel hand K-files by using computed tomography. J Endod 36:904-907 
Glossen CR, Haller RH, Dove SB, del Rio CE (1995) A comparison of root canal preparations using ni-ti hand, ni-ti engine-driven, and K-flex endodontic instruments. J Endod. 21:146-151

Haapasalo M, Shen Y (2013) Evolution of nickel-titanium instruments: from past to future. Endodontic topics. 29:3-17

Kim HC, Kim HJ, Lee CJ, Kim BM, Park JK, Versluis A (2009b) Mechanical response of nickel-titanium instruments with different cross-sectional designs during shaping of simulated curved canals. Int Endod J. 42:593-602

Kim TO, Cheung GSP, Lee JM, Kim BM, Hur B, Kim HC (2009a) Stress distribution of three NiTi rotary files under bending and torsional conditions using a mathematic analysis. Int Endod J 42:14-21

Lopes HP, Gambarra-Soares T, Elias CN et al (2013) Comparison of the mechanical properties of rotary instruments made of conventional nickel-titanium wire, M-wire, or nickel-titanium alloy in R-phase. J Endod 39:516-520

Ninan E, Berzins DW (2013) Torsion and bending properties of shape memory and superelastic nickel-titanium instruments. J Endod. 39:101-104

Park SY, Cheung GS, Yum J et al (2010) Dynamic torsional resistance of nickeltitanium rotary instruments. J Endod 36:1200-1204

Peters OA, Peters Cl, Schönenberger K, Barbakow F (2003) ProTaper rotary root canal preparation: Assessment of torque and force in relation to canal anatomy. Int Endod J. 36:93-99

Prados- Privado M, Rojo R, Ivorra C, Prados-Frutos JC (2019) Finite element analysis comparing WaveOne, WaveOne Gold, Reciproc and Reciproc Blue responses with bending and torsion tests. J of the mechanical behavior of biomedical materials 90:165-172

Ruddle CJ, Machtou P, West JD (2013) The shaping movement: fifth generation technology. Dent Today 32(94):96-99

Sattapan B, Nervo G, Palamara J, Messer H (2000) Defects in rotary nickel-titanium files after clinical use. J Endod. 26:161-165

Schafer E, Vlassis M (2004) Comparative investigation of two rotary nickel-titanium instruments: Protaper versus Race. Part 2: cleaning effectiveness and shaping ability in severely curved root canals of extracted teeth. Int Endod J. 37:239-248

Shen Y, Zhou HM, Zheng YF, Peng B, Haapasalo M (2013) Current challenges and concepts of the thermomechanical treatment of nickel-titanium instruments. J Endod. 39:163-172

Short JA, Morgan LA, Baumgartner JC (1997) A comparison of canal centering ability of four instrumentation techniques. J Endod 23:503-507

Turpin YL, Chagneau F, Vulcain JM (2000) Impact of two theoretical crosssections on torsional and bending stresses of nickel-titanium root canal instrument models. J Endod. 26:414-417

Varghese NO, Pillai R, Sujathen U, Sainudeen S, Antony A, Paul S (2016) Resistance to torsional failure and cyclic fatigue resistance of ProTaper Next, WaveOne, and Mtwo files in continuous and reciprocating motion: An in vitro study. J Conserv Dent 19:225-230

Walia HM, Brantley WA, Gerstein H (1988) An initial investigation of the bending and torsional properties of nitinol root canal files. J Endod. 14:346-351

Wu H, Peng C, Bai Y, Hu X, Wang L, Li C (2015) Shaping ability of ProTaper Universal, WaveOne and ProTaper Next in simulated L-shaped and S-shaped root canals. BMC Oral Health 15:27

Wycoff RC, Berzins DW (2012) An in vitro comparison of torsional stress properties of three different rotary NiTi files with similar cross sectional design. J Endod. 38:1118-1120

\section{Publisher's Note}

Springer Nature remains neutral with regard to jurisdictional claims in published maps and institutional affiliations.

\section{Submit your manuscript to a SpringerOpen ${ }^{\circ}$ journal and benefit from:}

- Convenient online submission

Rigorous peer review

- Open access: articles freely available online

- High visibility within the field

- Retaining the copyright to your article

Submit your next manuscript at $\boldsymbol{\nabla}$ springeropen.com 